\title{
SISTEM MANAJEMEN PENYIMPANAN PERANGKAT NETWORKING PADA APJII JAKARTA SELATAN
}

\author{
Rafiqi Faris Satriavi ${ }^{1}$, Aswin Fitriansyah ${ }^{2}$, Randi Ramliyana ${ }^{3}$ \\ Program Studi Teknik Informatika, Fakultas Teknik dan Ilmu Komputer, \\ Universitas Indraprasta PGRI \\ Jalan Raya Tengah No 80, Kelurahan Gedong, Pasar Rebo, Jakarta Timur \\ rafiqifaris@ymail.com ${ }^{1}$, aswin.fitriansyah@gmail.com ${ }^{2}$, randi.ramliyana@gmail.com ${ }^{3}$
}

\begin{abstract}
Abstrak
Tujuan dari penelitian ini adalah untuk mengetahui seperti apa sistem yang digunakan dalam manajemen penyimpanan perangkat networking yang ada pada APJII Jakarta Selatan. Metode penelitian yang digunakan untuk sistem manajemen perangkat networking ini adalah metode waterfall yang melakukan pendekatan secara sistematis dan berurutan. Hasil yang didapatkan dari penerapan aplikasi ini dapat mempermudah karyawan dalam bekerja dengan lebih baik dan lebih cepat dalam memanajemen penyimpanan perangkat networking. Selain itu peneliti berharap para pembaca dapat memahami dalam penggunaan suatu sistem aplikasi khususnya sistem manajemen perangkat networking. Oleh sebab itu peneliti mencoba membuat suatu sistem yaitu sistem manajemen penyimpanan perangkat networking menggunakan bahasa pemrograman Java dan MySQL sebagai database.
\end{abstract}

Kata Kunci : networking, manajemen penyimpanan perangkat, Netbeans IDE

\begin{abstract}
The purpose of this research is to find out what kind of system is used in the storage management of networking devices at APJII South Jakarta. The research method used for this networking device management system is the waterfall method which takes a systematic and sequential approach. The results obtained from implementing this application can make it easier for employees to work better and faster in managing networking device storage. In addition, the researcher hopes that readers can understand the use of an application system, especially a network device management system. Therefore, the researcher tries to create a system, namely a networking device storage management system using the Java programming language and MySQL as a database.
\end{abstract}

Keyword : networking, device storage management, Netbeans IDE

\section{PENDAHULUAN}

Dalam menempatkan perangkat jaringan di datacenter dibutuhkan adanya sistem manajemen yang mengelola penempatan perangkat jaringan tersebut didalam datacenter.Perangkat jaringan yang ada harus diidentifikasi, dikelola, dan dirawat dengan baik agar dalam pemakaiannya selalu optimal.Saat ini belum adanya sistem manajemen untuk pendataan penyimpanan perangkat jaringan yang berada di lingkungan kerja APJII yang dimana untuk melakukan pendataan penyimpanan perangkat masih menggunakan manual dengan menggunakan aplikasi spreadsheat (Ms.Excel), sehingga kesulitan dalam melakukan pendataan data secara efektif dan efisien. Berdasarkan masalah yang sudah peneliti paparkan, maka dari itu peneliti mempunyai sebuah gagasan untuk membuat sebuah sistem manajemen yang nantinya akan sangat bermanfaat bagi APJII.Menurut (Sutabri, 2012) Sistem adalah sekelompok unsur yang erat hubungannya satu dengan yang lain yang berfungsi bersama-sama untuk mencapai tujuan tertentu sehingga metode ini sangat cocok digunakan untuk penelitian ini untuk mengelola penempatan perangkat jaringan didalam datacenter.

Tujuan penelitian ini adalah sistem manajemen penyimpanan perangkat networking di bangun bertujuan untuk pengontrolan data penyimpanan perangkat networking sehingga dapat menghasilkan informasi secara terpadu, dan terdapat pengaruh bagi karyawan dari hasil pengujian sistem manajemen penyimpanan perangkat networking di datacenter APJII. Manfaat dari penelitian ini adalah untuk menghindari hilangnya perangkat jaringan dan dengan adanya sistem manajemen penyimpanan perangkat networking ini, maka operasional perusahaan dapat berjalan 
lebih baik lagi, dan menyediakan informasi yang cepat, tepat dan akurat mengenai data maupun laporan yang dibutuhkan serta memudahkan karyawan dalam melakukan pengkontrolan colocation perangkat.

\section{PENELITIAN RELEVAN}

Sistem manajemen adalah sebuah sistem manusia atau mesin yang terpadu (integrated) untuk menyajikan informasi guna mendukung fungsi operasi, manajemen, dan pengambilan keputusan dalam sebuah organisasi (Davis, 2010).Berdasarkan pemaparan (Hartono, 2013) maka dapat disimpulkan sistem manajemen adalah sebuah sistem yaitu rangkaian terorganisasi dari sejumlah atau komponen yang secara bersama-sama berfungsi atau bergerak menghasilkan informasi untuk digunakan dalam perusahaan.

Penyimpanan Perangkat/ Colocation data center adalah rack tempat meletakkan perangkat jaringan yang berada pada sebuah data center. Istilah colocation data center tentu saja berkaitan erat dengan data center. Colocation dan data center tidak bisa dipisahkan, jadi ibarat data center adalah rumah, maka colocation adalah furniture dan perabotan rumah. Keduanya berkaitan satu sama lain. Sebuah data center dibangun untuk menunjang kestabilan beberapa server yang terletak pada rack maupun kabinet-kabinet agar dapat berjalan dengan baik tanpa kendala.Sebuah data center memilki standard yang harus dipenuhi untuk dapat dikatakan sebagai data center dan layak memberikan layanan, baik itu standard ISO maupun standard sertifikasi Tier dari Uptime Institute. Berikut kriteria wajib yang dimiliki data center adalah tingkat pengamanan yang lebih tinggi selama 24 jam, tenaga listrik cadangan, personal IT 24 jam non-stop, lokasi bebas banjir, longsor, dan bencana lainnya, serta sistem pengaturan suhu ruangan dari segala arah. Hasil penelitian terdahulu yang dapat digunakan sebagai acuan antara lain.

1. Hasil penelitian (Malik, 2017), yang berjudul "Rancang Bangun Sistem Informasi Manajemen Pengelolaan dan Penjadwalan Layanan Konsultasi Bantuan Hukum Pada LBH Makassar", bertujuan untuk untuk membantu para staf LBH Makassar dalam mengelola penataan dan penyimpanan dokumentasi kasus client dengan baik dengan aplikasi web. Persamaan penelitian diatas dengan skripsi peneliti yaitu, membantu para staf dalam penataan dan penyimpanan. Perbedaan penelitian diatas dengan skripsi peneliti yaitu, menggunakan aplikasi web untuk penelitian diatas sedangkan pada skripsi peneliti menggunakan java.

2. Hasil penelitian (Syafarina, 2016), yang berjudul "Perancangan Aplikasi Inventory Barang Materials", bertujuan untuk pengontrolan stok barang terhadap transaksi pembelian, penjualan, dan pemesanan barang. Persamaan penelitian diatas dengan skripsi peneliti yaitu, sama-sama membantu kelancaran dalam pendataan barang. Perbedaan penelitian diatas dengan skripsi peneliti yaitu, pengaplikasian pada gudang sedangkan pada skripsi peneliti pengaplikasiannya pada data center.

\section{METODE PENELITIAN \\ Desain Penelitian}

Desain penelitian yang digunakan oleh peneliti dalam penelitian ini adalah waterfall. Model waterfall adalah "model klasik yang bersifat sistematis, berurutan dalam membangun software"(Pressman, 2015).

Alasan menggunakan metode ini adalah karena metode waterfall melakukan pendekatan secara sistematis dan berurutan dalam membangun suatu sistem. Proses metode waterfall yaitu pada pengerjaan dari suatu sistem dilakukan secara berurutan. Sistem yang dihasilkan akan berkualitas baik, dikarenakan pelaksanaannya secara bertahap sehingga tidak terfokus pada tahapan tertentu.

\section{Teknik Pengumpulan Data}

Teknik yang digunakan dalam pengumpulan data yaitu observasi secara langsung, wawancara, dan dengan studi pustaka.Observasi merupakan salah satu cara mengumpulkan data yang diperlukan dengan cara melakukan pengamatan dan meneliti secara langsung gejala atau peristiwa yang diselidiki oleh peneliti.Pengumpulan data melalui wawancara ini dilakukan untuk mencari data dan informasi tentang hal-hal yang dibutuhkan dalam penelitian. Wawancara dilakukan dengan lembaga atau instansi yang dijadikan objek penelitian.Sedangkan pada studi pustaka diperoleh dari berbagai 
sumber karya tulis ilmiah yang dapat dijadikan referensi dan mendukung penelitian yang dilakukan.

\section{Langkah Pengembangan Sistem}

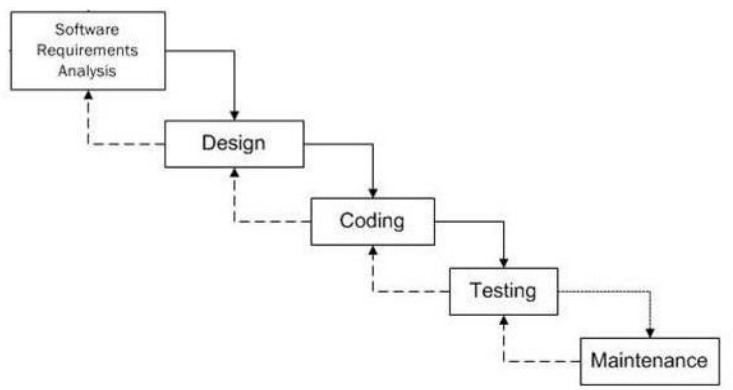

Gambar 2. Metode Waterfall

(Sumber : Mall, 2013)

Dalamfaseinipenelitimengidentifikasitujuanaplikasidansistemsertamengidentifikasiinformasikebutu han yang ditimbulkandaritujuantersebut. Kemudian fase perancangan peneliti melakukan proses perancangan dan desain sistem setelah melakukan analisa sistem yang berjalan pada perusahaan pada fase perencanaan kebutuhan. Pada fase pengujian peneliti melakukan pengujian terhadap aplikasi dan sistem yang telah sebelum masuk ke dalam fase implementasi, apakah sistem tersebut berjalan dengan baik atau terdapat error. Pada fase implementasi peneliti melakukan pengujian dan testing terhadap aplikasi dan sistem tetapi tidak melakukan sosialisasi terhadap aplikasi dan sistem yang telah dibuat.

\section{HASIL DAN PEMBAHASAN}

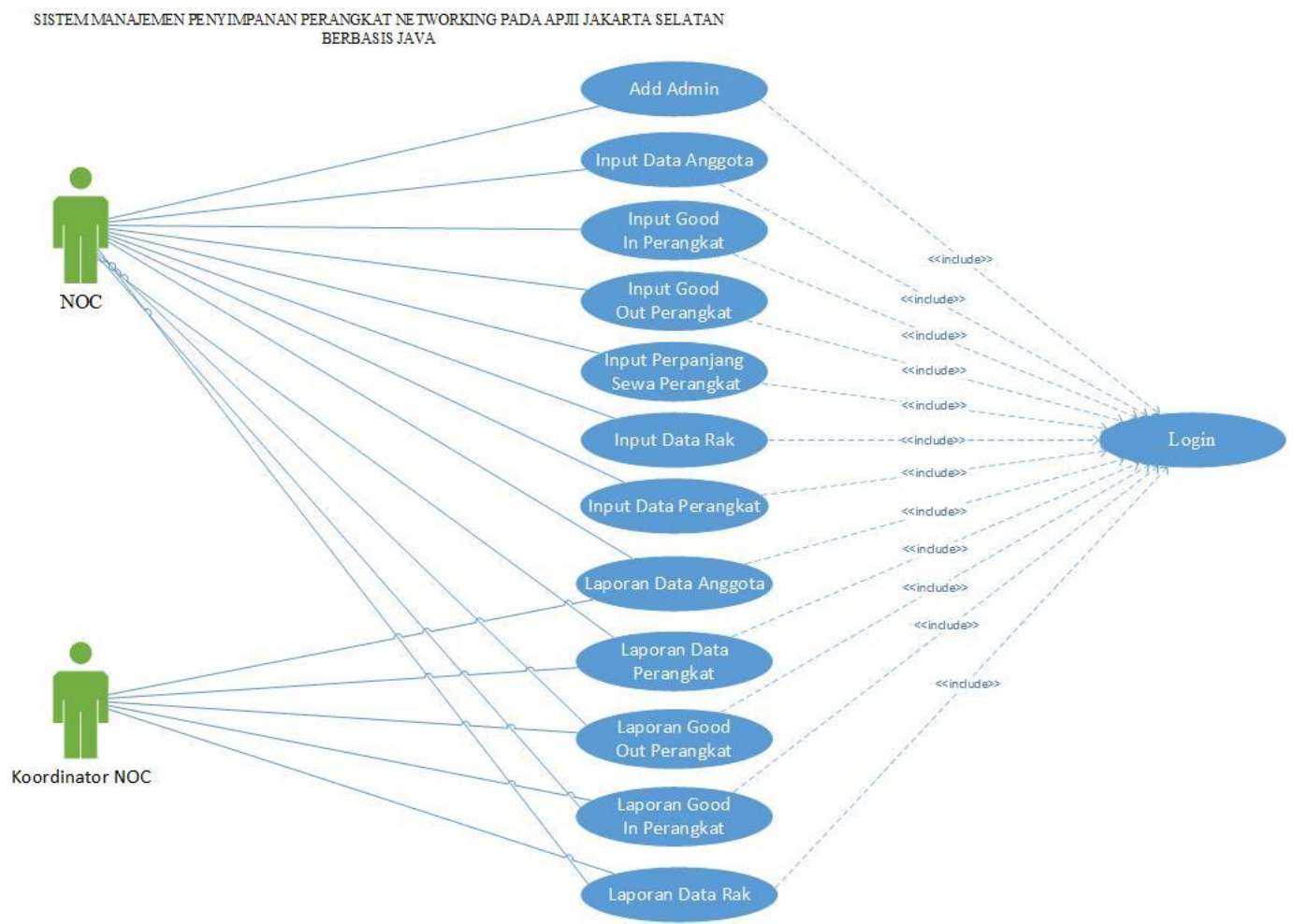

Gambar 2.Use Case Diagram 
Pada gambar 2 adalah use case diagram untuk penelitian ini yang dimana terdapat 2 aktor yaitu NOC dan Koordinator NOC.

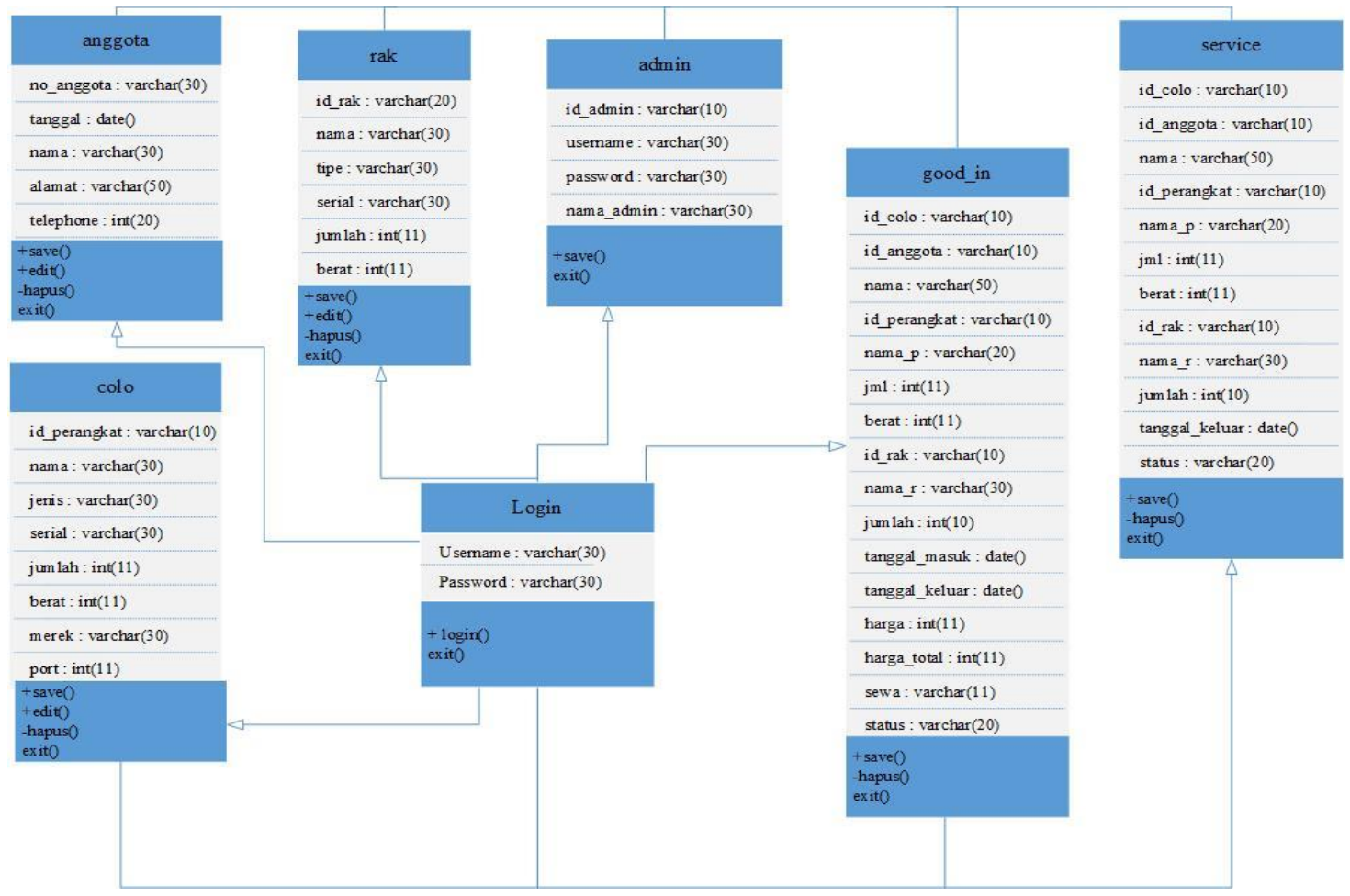

Gambar 3.Class Diagram

Pada gambar 3 merupakan tampilan class diagram yang menggambarkan struktur class pada penelitian ini. Terdapat 7 class pada penelitian ini yang terdiri dari class anggota, class rak, class admin, class login, class good_in, class colo, dan class service.

\section{Hasil Analisis Rancangan Layar}

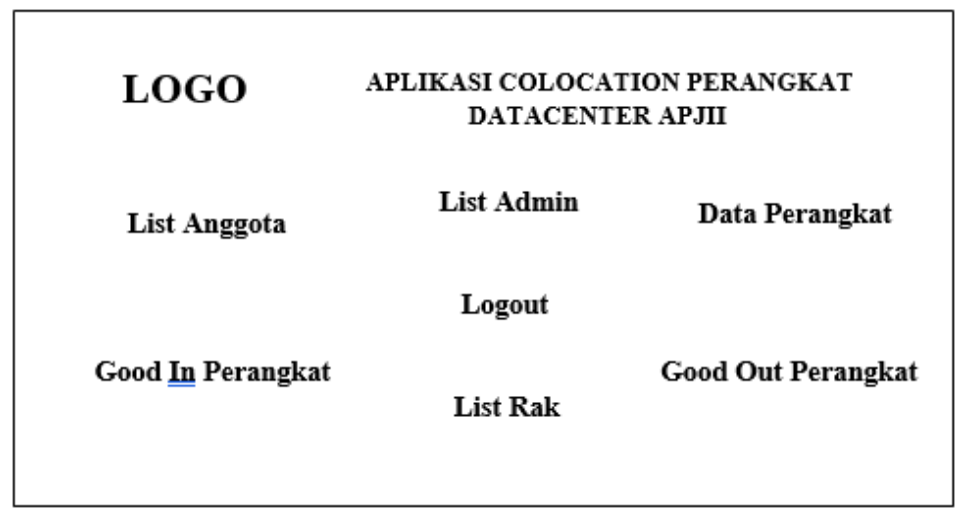

Gambar 4. Rancangan Menu Home

Pada gambar 4 merupakan tampilan pada menu utama/home yang dimana operator atau admin dapat melakukan penginputan data seperti data anggota, data perangkat dan melakukan transaksi good in, perpanjangan masa sewa, dan good out perangkat networking. 


\section{Tampilan Aplikasi}

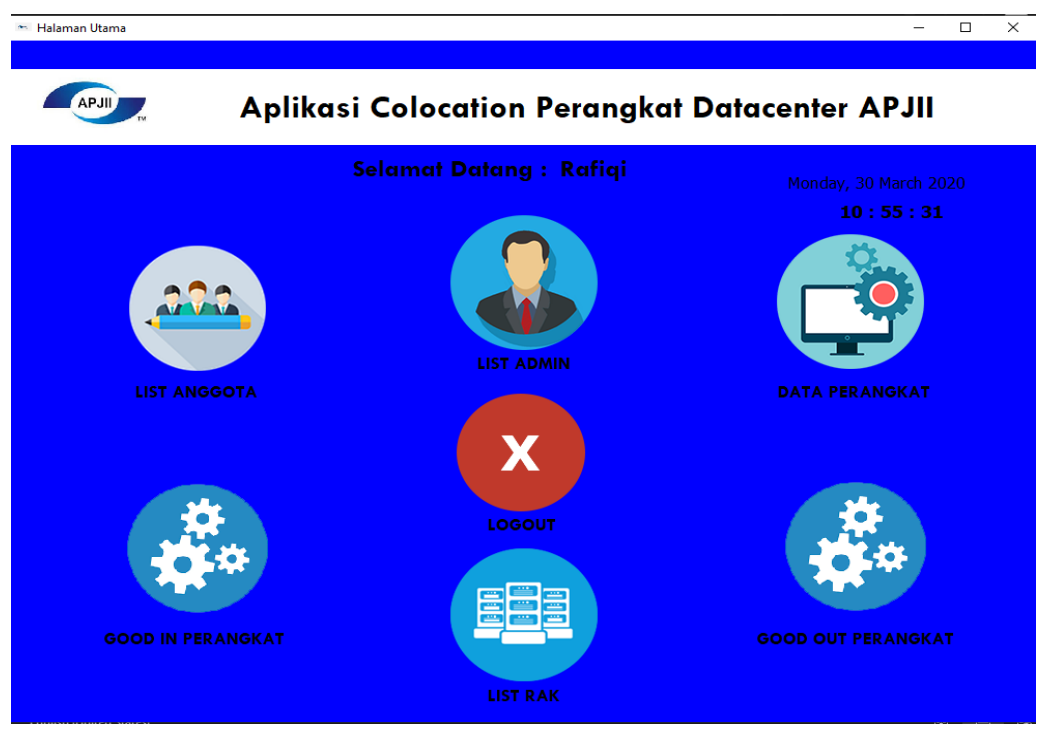

Gambar 5. Tampilan Menu Home

Gambar 5 diatas merupakan tampilan menu utama setelah berhasil login.

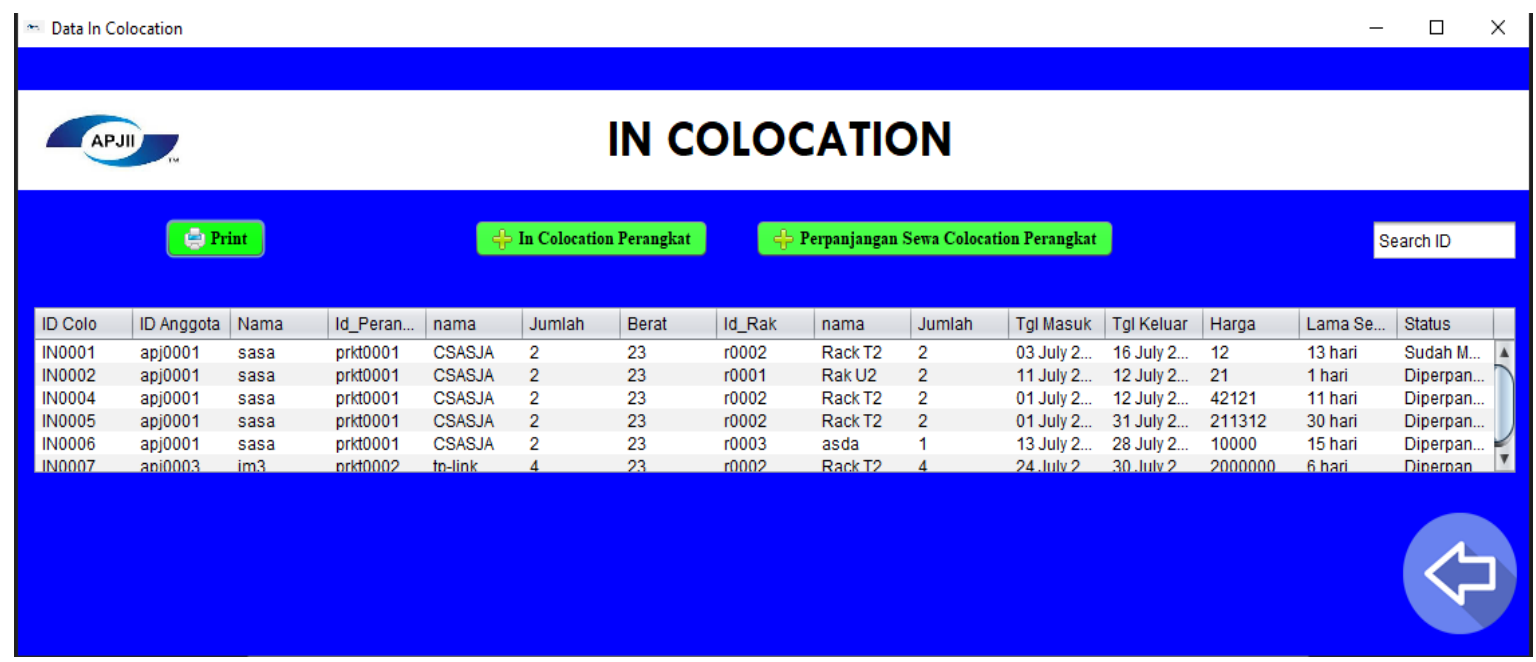

Gambar 6. Tampilan Menu Good In

Gambar 6 diatas merupakan tampilan menu good in yang digunakan untuk proses permintaan masuk perangkat networking ke dalam data center. Pada menu tersebut berisikan berisikan id anggota, nama anggota, id perangkat, nama perangkat, jumlah perangkat, nama rak, dan dimensi(ukuran), harga/slot, harga sewa, tanggal sewa dan tanggal habis. 


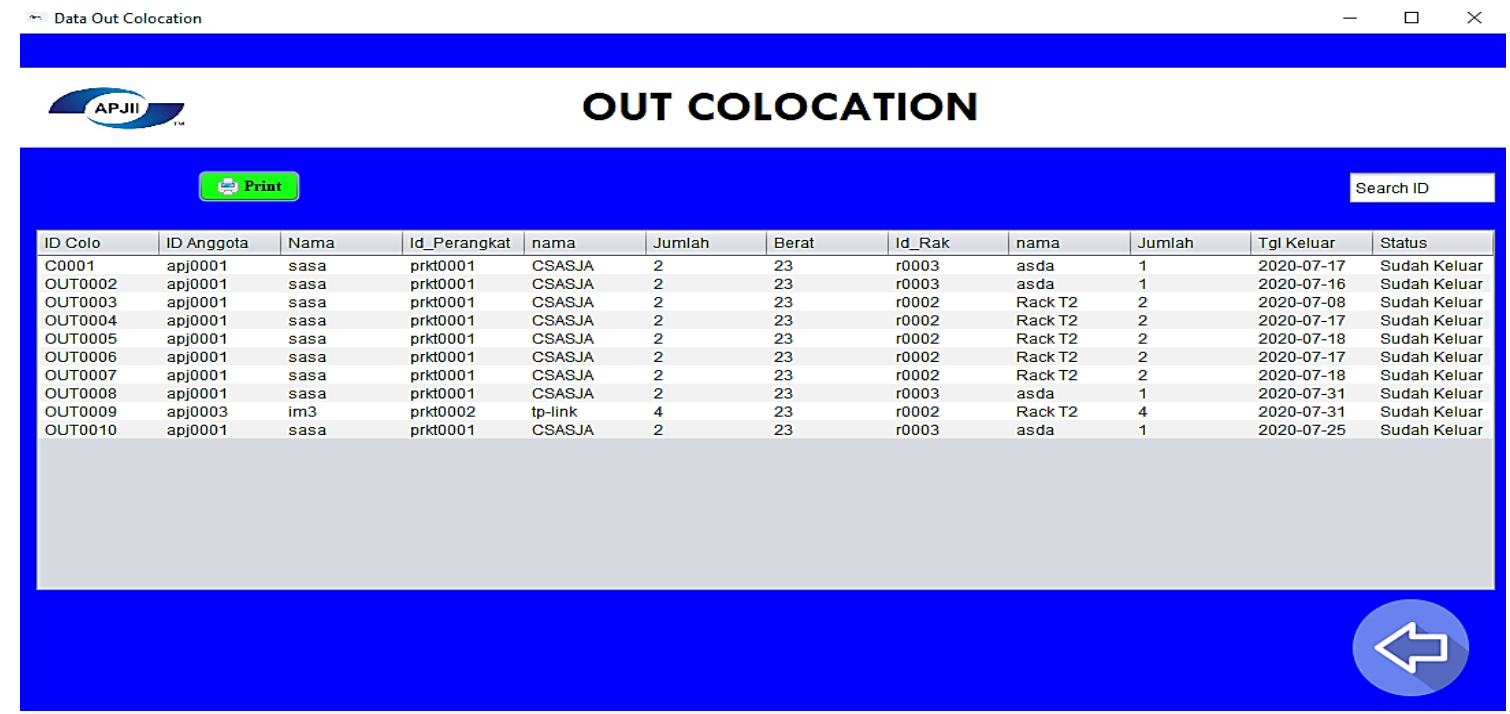

Gambar 7. Tampilan Menu Good Out

Gambar 7 diatas merupakan tampilan menu good out perangkat networking dari dalam data center. Pada menu tersebut berisikan id colo, id anggota, nama anggota, id perangkat, nama perangkat, jumlah perangkat, berat perangkat, id rak, nama rak, jumlah/U, tanggal keluar, dan status.

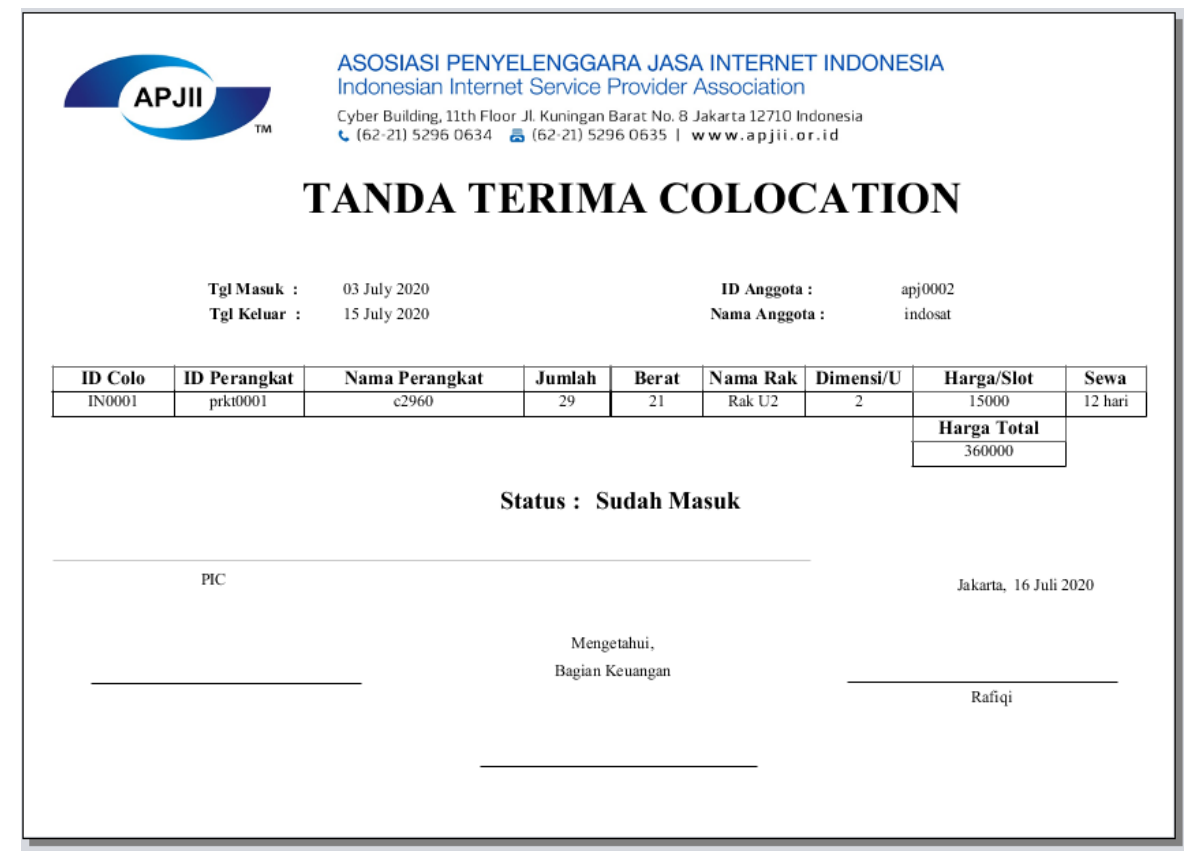

Gambar 8. Tampilan Laporan Good In

Gambar 8diatas merupakan laporan good in perangkat networking yang sudah masuk ke dalam data center.

\section{SIMPULAN}

Kesimpulan yang dapat diperoleh dari penelitian ini yaitu :

1. Sistem manajemen penyimpanan perangkat networking di bangun bertujuan untuk pengontrolan data penyimpanan perangkat networking sehingga dapat menghasilkan informasi secara terpadu.

2. Terdapat pengaruh bagi karyawan dari hasil pengujian sistem manajemen penyimpanan perangkat networking di datacenter APJII. 


\section{DAFTAR PUSTAKA}

Anhar. (2010). PHP \& MySql Secara Otodidak. Jakarta: PT TransMedia.

Arief, M. (2011). Pemrograman Web Dinamis menggunakan PHP dan MySQL. Yogyakarta: Andi Offset.

Buana. (2014). Jago Pemograman. Jakarta: Dunia Komputer.

Davis, K. (2010). Perilaku Dalam Organisasi. Jakarta: Erlangga.

Hasibuan, M. (2013). Manajemen Sumber Daya Manusia. Jakarta: PT Bumi Aksara.

Ladjamudin. (2013). Analisis dan Desain Sistem Informasi. Yogyakarta: Graha Ilmu.

Pressman, R. (2015). Rekayasa Perangkat Lunak : Pendekatan Praktisi Buku. Yogyakarta: Andi Offset.

Safroni. (2012). Manajemen dan Reformasi Pelayanan Publik dalam Konteks Birokrasi Indonesia (Teori, Kebijakan, dan Implementasi). Yogyakarta: Aditya Media Publishing.

Shalahuddin, M. d. (2014). Rekayasa Perangkat Lunak Terstruktur dan Berorientasi Objek. Bandung: Informatika.

Sugiarti, Y. (2013). Analisis dan Perancangan UML (Unified Modeling Language). Yogyakarta: Graha Ilmu.

Supardi. (2010). Penelitian Tindakan Kelas. Jakarta: PT Bumi Aksara.

Susanto. (2013). Sistem Informasi Akuntasi. Bandung: Lingga Jaya.

Sutabri. (2012). Analisis Sistem Informasi. Yogyakarta: Andi Offset. 